\title{
One-Step Electrosynthesis of Graphene Oxide-Doped Polypyrrole Nanocomposite as a Nanointerface for Electrochemical Impedance Detection of Cell Adhesion and Proliferation Using Two Approaches
}

\author{
Yuan Li ${ }^{1,2}$ and Chao Yu ${ }^{1}$ \\ ${ }^{1}$ Institute of Life Science, Chongqing Medical University, Chongqing 40016, China \\ ${ }^{2}$ Yongchuan Hospital, Chongqing Medical University, Chongqing 402160, China \\ Correspondence should be addressed to Chao Yu; yuchaom@163.com
}

Received 20 November 2015; Revised 8 January 2016; Accepted 1 June 2016

Academic Editor: Silvia Licoccia

Copyright (C) 2016 Y. Li and C. Yu. This is an open access article distributed under the Creative Commons Attribution License, which permits unrestricted use, distribution, and reproduction in any medium, provided the original work is properly cited.

\begin{abstract}
A novel nanointerface of graphene oxide-doped polypyrrole (GO/PPy) is prepared on the surface of an indium tin oxide (ITO) electrode for electrochemical impedance detection of cell adhesion and proliferation through a facile one-step electropolymerization. The prepared GO/PPy nanocomposite had a robust surface and provided a biocompatible substrate for A549 cells adhesion and proliferation. The adhesion and proliferation of A549 cells on the surface of the GO/PPy modified ITO electrode directly increased the electron transfer resistance of $\left[\mathrm{Fe}(\mathrm{CN})_{6}\right]^{3-/ 4-}$ redox probe and influenced the impedance properties of the GO/PPy modified ITO electrode system. Based on these results, the adhesion and proliferation of A549 cells could be detected by electrochemical impedance technology using two approaches. Therefore, the present paper confirms that the GO/PPy nanocomposite film provides an excellent biological-electrical interface for cell immobilization and offers advantages of simple, low-cost fabrication and multiparameter detection and possesses potential application in cytological studies.
\end{abstract}

\section{Introduction}

With the development of nanobiotechnology, various nanocomposite materials based on observed synergistic effects have found widespread applications in the fields of biomaterials [1], drug delivery [2], and detection of molecules [3]. In addition to the special structure, electrochemical properties, and catalytic activity of graphene (GN), graphene oxide (GO), an oxidized derivative of $\mathrm{GN}$, is rich with various oxygenated functional groups at its basal plane and edges, including hydroxide, epoxide, carbonyl, and carboxyl groups $[4,5]$. Therefore, GO exhibits better water solubility than does GN, which is beneficial for the construction of nanocomposites. To date, great efforts have been made to develop GO-based nanomaterials and explore their applications in biosensors $[6,7]$, electronics and optoelectronics [8], drug delivery [9], enzyme immobilization [10], and so forth. More importantly,
Chang et al. [11] used different cytotoxic tests to evaluate the cytotoxicity of GO with different sizes on A549 cells. The results revealed that GO exhibits excellent cell biocompatibility. Zhang et al. [12] constructed a GO/PLL biocompatible nanocomposite through electrostatic assembly and demonstrated that this composite can be used as the interface to anchor cells. The authors also used electrochemical impedance spectroscopy to quantitatively detect leukemia K562 cancer cells. Guo et al. [13] reported that modification of GO with RGD-peptide can further improve the biomimetic function of GO for the detection of nitric oxide molecules as live-cell sensors. Undoubtedly, the development of GObased nanocomposites is an important direction for the construction of novel cell-based sensors.

Polypyrrole (PPy) is an important conjugated conducting polymer that possesses advantages including intrinsic conductance, controllable surface properties, excellent 
biocompatibility, and low-potential electropolymerization preparation. PPy can be used as the anchoring matrix for biomolecules such as DNA [14], enzymes [15], and antibodies [16] and more recently as cell growth surfaces [17]. In particular, PPy can also be used as potential electrode coating for electrochemical detection of cell behaviors due to the combinations of biocompatibility and conductivity $[18,19]$. However, these reports are limited. The reason may be that pure PPy is usually mechanically weak, electrochemically instable, and insulating in its neutral state, in turn compromising the detection performances of cell sensors. To improve the mechanical and electrochemical properties of PPy, various nanomaterials, including gold nanoparticles [20] and carbon nanofiber [21], have been integrated into PPy to form unique PPy/nanocomposites. Because of the unique properties of GN and its derivatives, researchers have reported the coupling of GN or its derivatives with PPy to form GN/PPy nanocomposites and have demonstrated that the constructed nanocomposite is characterized by synergistic effects between PPy and GN [22, 23]. For example, the novel multilayered nanoarchitecture of graphene and PPy was developed by stacking PPy and graphene nanosheets [24]. Mini et al. [23] developed a highly capacitive electrode made of GN/PPy composites and the preparation process involves the electrophoretic deposition of graphene upon which the PPy layer was electropolymerized. Recently, Zhu et al. [25] synthesized GO/PPy nanocomposite on a glassy carbon electrode through one-step electrodeposition for the preparation of high-performance electrochemical supercapacitors. Lv et al. [26] modified a layer of GO/PPy nanocomposite on the graphite felt electrode through one-step electropolymerization and demonstrated the improvement of anode stability and electricity generation for a microbial fuel cell. In the aforementioned studies $[25,26]$, GO could be used as the only external dopant in the electropolymerization of pyrrole [27]. The preparation of GO/PPy nanocomposite through one-step electropolymerization is simple and easy to realize. Furthermore, the prepared GO/PPy nanocomposite can improve the conductivity and stability of PPy as well as the adhesion between GO and electrodes. However, to the best of our knowledge, no research has been reported concerning the interaction between the GO/PPy nanocomposite prepared by one-step electropolymerization and cells or concerning the use of such nanocomposite as a nanointerface for detection of cells.

Electrochemical methods have attracted considerable attention to detecting live cells numbers $[12,28]$, constructing electrical impedance based sensing system to track the morphological change of adherent cells [29, 30], and monitoring immobilized cell response to drugs [31]. Compared with optical analysis methods, electrochemical analysis exhibits higher sensitivity, can distinguish the bioconjugation events at the sensor interface, and is easier for the quantification of signals and the presentation of information. Among the various electrochemical analytical techniques, electrochemical impedance spectroscopy (EIS) uses an alternating current (AC) of small amplitude as the disturbance signal and records the impedance data corresponding to different frequencies for the analysis of the impedance characteristics of the electrode system. Because a voltage signal with very small amplitude (less than $10 \mathrm{mV}$ ) is used in EIS, this method is considered noninvasive [31]. Currently, although a series of biosensors based on EIS have been developed for the analysis of cellular activity and function [28-32], most of the biosensors involve complicated preparation. At the same time, the cellular information obtained from the biosensors is limited. Therefore, investigation is valuable to simplify the preparation process and to improve the detection information obtained from these biosensors.

In the present study, we used a simple, one-step electropolymerization approach to synthesize GO/PPy nanocomposite film in situ and investigated the feasibility of applying the film as the nanointerface between biological cells and electrochemical impedance spectroscopy. The scheme for the one-step preparation of GO/PPy nanocomposite film is presented in Figure 1. ITO glass was chosen as the electrode in the experiment because of its conductance and transparency, which allows the in situ electropolymerization of PPy, EIS detection, and morphological observation of the interaction between the cells and the GO/PPy nanocomposite [33]. The obtained GO/PPy nanocomposite exhibited good electrochemical and physical properties. Meanwhile, human lung cancer epithelial cells A549 were used as the cell culture model and the results revealed that the GO/PPy nanocomposite film exhibited excellent biocompatibility. Furthermore, the adhesion and proliferation of A549 cells to GO/PPy nanocomposite film changed the electron transfer impedance of the electrochemical redox probe and also caused changes to the electrochemical impedance characteristic of the electrode system. Together, these results form the basis of two effective detection approaches in the construction of new electrochemical impedance biosensors for cells.

\section{Materials and Methods}

2.1. Materials and Equipment. GO, with a diameter of $50 \mathrm{~nm}-$ $100 \mathrm{~nm}$ and purity of $>99 \%$, was purchased from JCNANO Co., Ltd. (Nanjing, China). Pyrrole was purchased from Sigma Aldrich, distilled under nitrogen protection, subpackaged, and stored at $-20^{\circ} \mathrm{C}$ before use. ITO conductive glass was purchased from Zhuhai Kaivo Optoelectronic Technology Co., Ltd. (China), with a conductive thickness of $2200 \pm 300 \mathrm{~nm}$ and an area resistance of $\leq 7 \Omega /$ square. The ITO conductive glass was sequentially cleaned in acetone, ethanol, and distilled deionized (DDI) water for $15 \mathrm{~min}$ each with ultrasonication. The WST-8 assay kit was purchased from Beyotime Institute of Biotechnology (China). Other regents were of analytical grade, and the solutions were prepared using Millipore Milli-Q DI water (18 M $\Omega$ ).

Fourier transform infrared spectroscopy (FTIR) was performed on a Magna-IR 750. Morphological observations were performed on a Phenom Pro desktop scanning electron microscope (SEM). Cell micromorphology observations were performed on an inverted fluorescence microscope (Olympus IX71, Japan). The roughness and thickness of the PPy films were measured using a VK-V150 laser microscope system (Keyence, Japan). The roughness was investigated by measuring the surface three times per sample at different 


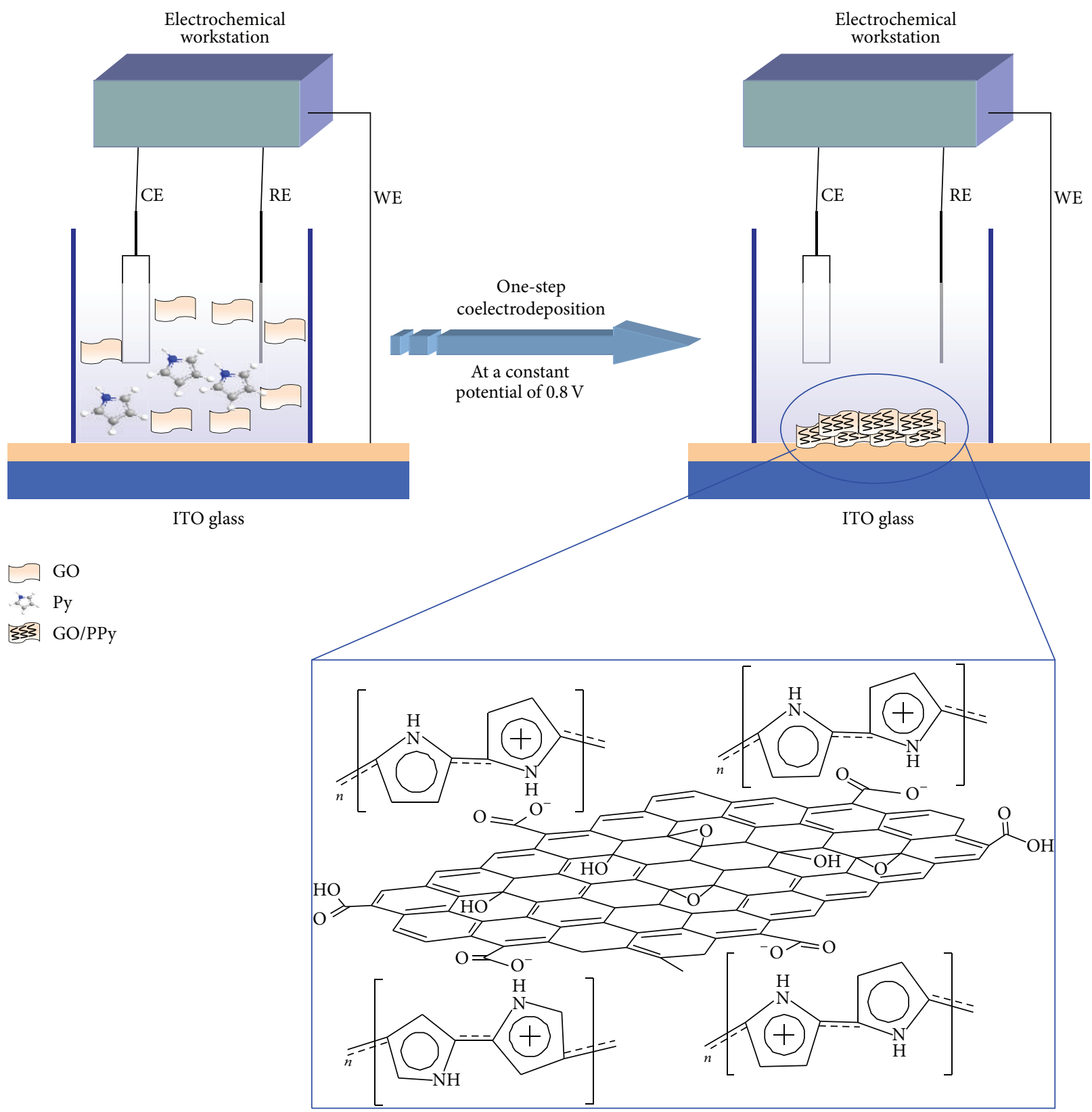

FIGURE 1: Schematic diagram of the one-step electrosynthesis of GO/PPy nanocomposites via electropolymerization of pyrrole using GO as the sole dopant.

locations and the thickness was measured three times per sample at different locations at the PPy boundary. The surface energy of PPy films was measured by a SCI3000F optical contact angle meter (Henda, China). All electrochemical experiments were performed on a CS350 electrochemical station (Wuhan Corrtest Instrument Co., Ltd., China). Electropolymerization, cell culture, and electrochemical impedance spectroscopy were also performed in a small home-made electrolytic cell. The schematic and the actual picture of the electrolytic microcell are presented in Figure 2. The volume of each electrolytic cell was $500 \mu \mathrm{L}$. A three-electrode system was used in the electrochemical experiments. The ITO electrode placed in the bottom of the electrolytic cell was used as the working electrode (the diameters of the electrode were $5 \mathrm{~mm}$ and $0.5 \mathrm{~mm}$, resp.), the platinum wire was used as the auxiliary electrode, and the $\mathrm{Ag} / \mathrm{AgCl}$ wire was used as the reference electrode.

2.2. Electropolymerization of GO/PPy Nanocomposite Film. GO was dissolved in DDI water without any treatment and was sonicated for $15 \mathrm{~min}$ to form a homogeneous dispersion with a concentration of $2 \mathrm{mg} \mathrm{mL}^{-1}$. Pyrrole was added to the GO solution to reach a pyrrole concentration of $0.5 \mathrm{~mol} \mathrm{~L}^{-1}$, and the mixture was vortexed to obtain the prepolymerization solution. The constant potential method was used for the electropolymerization of the GO/PPy nanocomposite; 


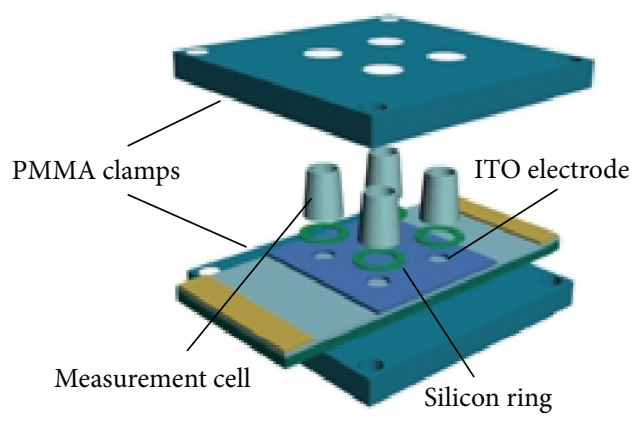

(a)

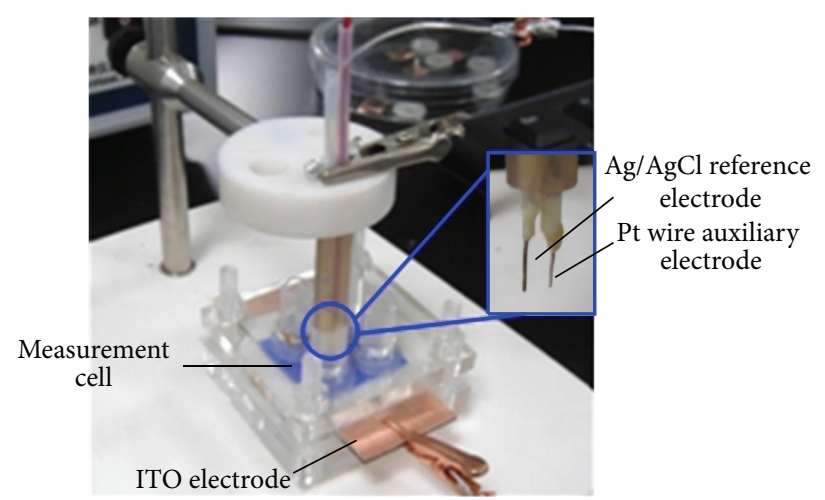

(b)

FIgURE 2: House-made electrolytic cell. (a) Structure diagram. (b) Picture.

that is, a constant polarization potential of $+0.8 \mathrm{~V}$ (versus $\mathrm{Ag} / \mathrm{AgCl}$ ) was applied to the ITO electrode. The thickness of the GO/PPy nanocomposite could be controlled by the polymerization charge. Our preexperiment revealed that a homogeneous and stable nanocomposite film can be formed on the surface of the ITO electrode with a diameter of $5 \mathrm{~mm}$ when the polymerization charge was $0.02 \mathrm{Ccm}^{-2}$. The thickness calculated with a theoretical equation was estimated to be $209 \mathrm{~nm}$ [34]. The GO/PPy nanocomposite was then rinsed with DDI water and dried at room temperature. As a control, pure PPy film was obtained by electropolymerization in a solution containing $0.1 \mathrm{M} \mathrm{KCl}$ and $0.5 \mathrm{M}$ Py.

2.3. Cell Culture. A549 cells were routinely cultured at $37^{\circ} \mathrm{C}$ with $5 \% \mathrm{CO}_{2}$ in RPMI-1640 medium (Gibco) supplemented with $10 \%$ fetal bovine serum (Gibco), $100 \mathrm{U} \mathrm{mL}^{-1}$ penicillin, and $100 \mu \mathrm{g} \mathrm{mL}^{-1}$ streptomycin within an incubator. After the A549 cells grew into a monolayer, the cells were harvested by trypsinization with $0.25 \%$ trypsin and centrifuged at $1500 \mathrm{rpm}$ for $4 \mathrm{~min}$. A549 was stained by trypan blue for cell counting.

The GO/PPy nanocomposite film was sterilized using $70 \%$ ethanol and was rinsed with sterilized DDI water. The A549 cell suspension $(100 \mu \mathrm{L})$ at a concentration of $5.0 \times$ $10^{4}$ cells $\mathrm{mL}^{-1}$ was added to the electrolytic cell, which was subsequently placed into an incubator set at $37^{\circ} \mathrm{C}$ and $5 \%$ $\mathrm{CO}_{2}$. A549 cells precipitated to the surface of the GO/PPy nanocomposite film at the bottom of the electrolytic cell. The adhesion morphology of the A549 cells cultured for 2 hours on the surface of pure PPy and GO/PPy was observed by optical microscopy. A549 cells cultured for 12 hours were fixed using $4.0 \%$ paraformaldehyde, and the cellular spreading morphology was observed by laser microscope system. The proliferative activity of the A549 cells cultured on the surface of GO/PPy for $24 \mathrm{~h}$ and $48 \mathrm{~h}$ was analyzed by WST- 8 assay. Pure PPy, bare ITO, and polystyrene for tissue culture were used as controls. For the WST- 8 assays, $10 \mu \mathrm{L}$ of WST-8 reagent was added to each electrolytic cell and was incubated at $37^{\circ} \mathrm{C}$ for 1 hour. Culture medium $(100 \mu \mathrm{L})$ was taken out of the electrolytic cell to measure the absorbance value at $450 \mathrm{~nm}$.

2.4. Measurement of Cell-Electrochemical Impedance. An A549 cell suspension $(100 \mu \mathrm{L})$ at a concentration of $5.0 \times 10^{4}$ cells $\mathrm{mL}^{-1}$ was seeded into the electrolytic cell containing the GO/PPy nanocomposite film. The electrolytic cell was incubated for $2 \mathrm{~h}, 24 \mathrm{~h}, 48 \mathrm{~h}$, or $72 \mathrm{~h}$ in an incubator. The GO/PPy nanocomposite film was rinsed with 0.01M PBS to remove the nonadhered and dead cells. The reference electrode and counter electrode were subsequently inserted into the electrolytic cell for the measurement of the electrochemical impedance. The measurement was performed in two different electrolyte solutions. The first was a $0.01 \mathrm{PBS}$ ( $\mathrm{pH} 7.4$ ) solution containing $0.02 \mathrm{M} \mathrm{K}_{3} \mathrm{Fe}(\mathrm{CN})_{6} / \mathrm{K}_{4} \mathrm{Fe}(\mathrm{CN})_{6}$ $(1: 1)$ and $0.1 \mathrm{M} \mathrm{KCl}$. The second was a $0.01 \mathrm{MPBS}(\mathrm{pH} 7.4)$ solution. The measurement of the electrochemical impedance was performed by applying a sinusoidal alternating detection signal with an amplitude of $10 \mathrm{mV}$ under open circuit voltage; the frequency range of the signal was $1 \mathrm{~Hz} \sim 10^{5} \mathrm{~Hz}$. At least three measurements were made for each electrode. The electrochemical impedance data were analyzed by ZView 2.0 software (Scribner Associates, Southern Pines, NC, USA). In the first electrolyte solution, the cell proliferative activity was quantified by the electron transfer impedance of redox probe. In the second electrolyte solution, the cell proliferation affected the characteristics of the electrode impedance. By establishing equivalent circuit models, the electrochemical impedance data were fitted for the analysis and quantification of cell adhesion and proliferation. It is worth mentioning that, in the measurement of the second electrolyte solution, $\mathrm{GO} / \mathrm{PPy}$ was electropolymerized on the surface of the ITO microelectrode with a diameter of $500 \mu \mathrm{m}$ such that the measured electrochemical impedance was controlled by the ITO working electrode [35].

2.5. Statistics. Statistics analysis of surface characteristics of PPy film was performed using $t$-tests. For experiments with cell proliferation, one-way repeated measure analysis of variance (ANOVA) was used with paired-samples $t$-tests for 


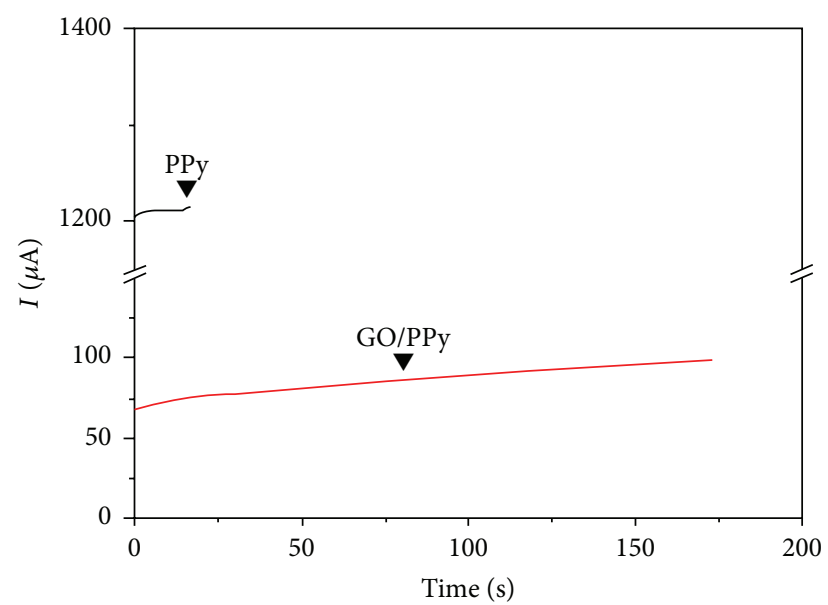

(a)

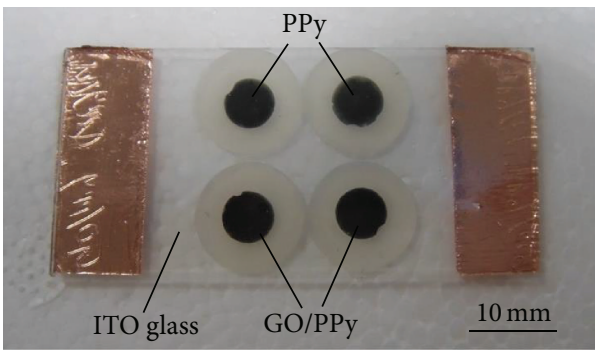

(b)

Figure 3: (a) Current-time curves recorded during the electropolymerization of $0.5 \mathrm{M}$ Py in an aqueous solution of $2 \mathrm{mg} \mathrm{mL}^{-1}$ (red line) and $0.1 \mathrm{M} \mathrm{KCl}$ (black line). Each film was electropolymerized until the charge passed was $0.02 \mathrm{Ccm}^{-2}$. The applied potential was $0.8 \mathrm{~V}$. (b) Pictures of pure PPy film and GO/PPy film electrodeposited on one ITO glass. The diameters of both films were $5 \mathrm{~mm}$.

post hoc comparisons. All data were presented as mean \pm SD. A $p$ value $<0.05$ was considered to be statistically significant.

\section{Results and Discussion}

3.1. One-Step Electropolymerization and Surface Characterization of GO/PPy Nanocomposite. To monitor the electropolymerization process of $\mathrm{Py}$ in $\mathrm{GO}$ and $\mathrm{KCl}$ solutions, we recorded the current-time $(i-t)$ curve for the electropolymerization of Py under $+0.8 \mathrm{~V}$ polymerization voltage, as shown in Figure 3(a). The results demonstrate that the polymerization current for Py was smaller in GO aqueous solution than in $\mathrm{KCl}$ solution. This finding is attributed to the poor conductivity and the intrinsically poor electrolyte characteristic of GO. Therefore, under the same electropolymerization charge, the electropolymerization of the GO/PPy nanocomposite took longer time than for pure PPy. These results are consistent with those reported in the literature [25]. In addition, no current was produced under the same polymerization voltage when only GO or Py was present in solution, indicating that GO is the necessary dopant for the electropolymerization of Py. Furthermore, because of the ionization of the hydroxide and carboxyl groups on the GO surface, the zeta potential of GO was about $-50.7 \mathrm{mV}$ [36]. As a result, in the electropolymerization of $\mathrm{Py}$, the negative charge-bearing GO acted as the sole dopant to balance the positive charges on the PPy backbone, thus forming the $\mathrm{GO} / \mathrm{PPy}$ nanocomposite. At the same time, the $\pi-\pi$ stacking and hydrogen bonding between GO and the aromatic ring of PPy also played important roles in the formation of the GO/PPy nanocomposite [25]. Figure 3(b) presents the digital photos of the pure PPy film and the GO/PPy nanocomposite film on the surface of the ITO electrode prepared by the one-step electropolymerization. The PPy and GO/PPy films exhibited an integral structure and uniform thickness. Under the same electropolymerization parameters, it was observed by the naked eye that GO/PPy film exhibited a darker color, denser structure, and stronger adhesion to the surface of the ITO electrode than those of pure PPy.

Surface topography and wettability are important parameters commonly discussed for surface characterization of biomaterials. The type of dopant has a major influence on the surface topography and hydrophilicity of electrochemically polymerized polymer. These surface properties in turn affect cell biobehaviors [37]. In the current study, the surface properties of GO-doped PPy were systematically studied. Figure 4(a) presents the SEM images of the GO/PPy nanocomposite prepared by the one-step electropolymerization. Compared with the typical cauliflower structure characteristics of the pure PPy, GO/PPy nanocomposite exhibited more smooth surfaces and was featureless. Further observation of the edges of the nanocomposite demonstrated that the GO/PPy nanocomposite consisted of overlapping two-dimensional nanosheets. This result is different from the GO/PPy nanocomposite reported in the literature [26], whose surface exhibited a highly porous structure. This difference could be due to the difference in the size of the GO and the thickness of the prepared nanocomposite. Surface roughness and thickness were further measured by laser microscope system; three-dimensional topology morphology images (Figure 4(b)) showed GO/PPy had a very smooth surface, while PPy had a typical nodular feature. Calculated form Figure 4(b), the roughness value of the GO/PPy $(\mathrm{Ra}=$ $0.007 \pm 0.02 \mu \mathrm{m}$ ) was significantly lower than that of PPy $(\mathrm{Ra}=2.67 \pm 0.51 \mu \mathrm{m})$ (Figure $4(\mathrm{c}))$, indicating that low degree of roughness of GO/PPy surface is more preferable for adherent cells than micro-scale roughness PPy surfaces [38]. Meanwhile, the thickness of GO/PPy $(323 \pm 38 \mathrm{~nm})$ appeared to be thinner than that of PPy $(564 \pm 67 \mathrm{~nm})$ (Figure 4(d)). It indicated that GO/PPy has a more compact structure than PPy. Figure 4(e) showed GO/PPy and PPy had contact angles 


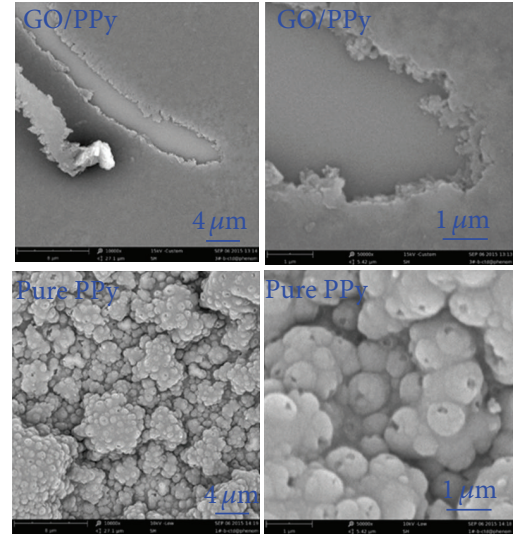

(a)

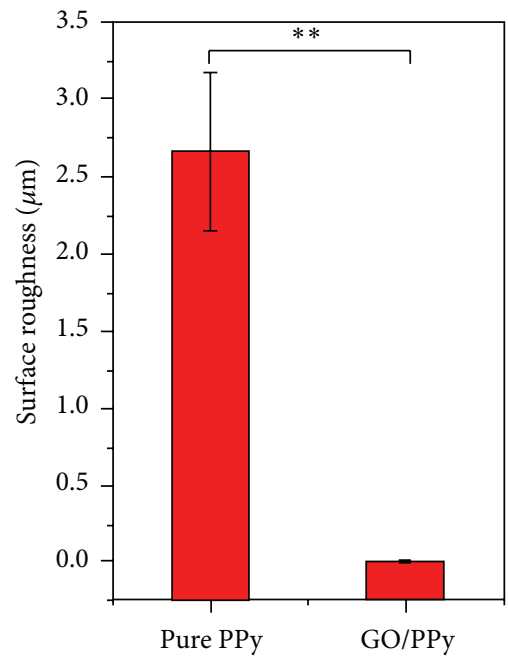

(c)
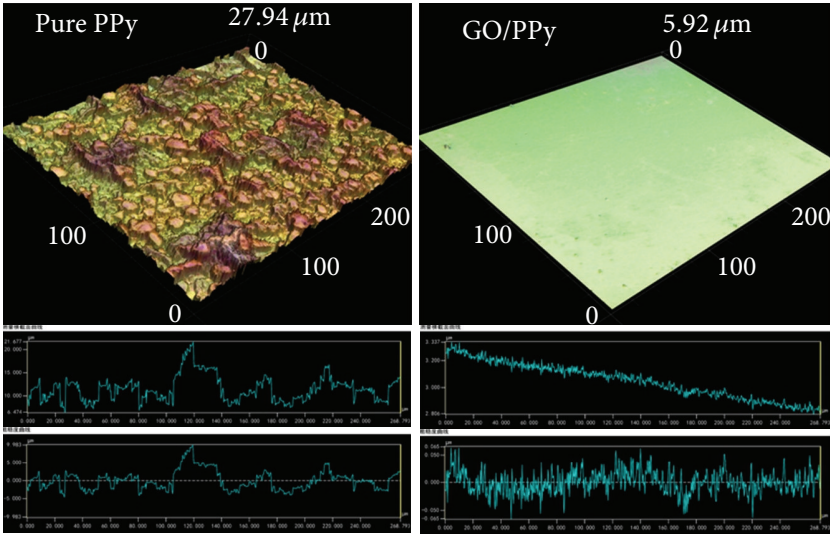

(b)

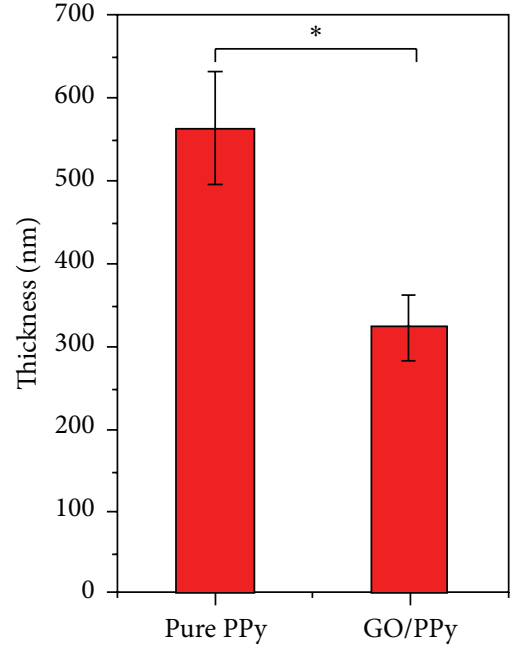

(d)

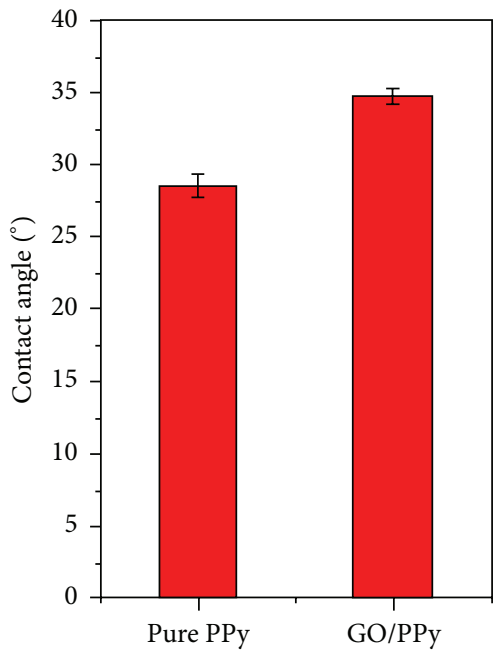

(e)

FIgURE 4: Surface characterization. (a) SEM images of the synthesized GO/PPy nanocomposites and pure PPy. (b) Three-dimensional topology morphology images of GO/PPy and pure PPy. (c) Surface roughness analysis, (d) thickness analysis, and (e) contact angle test of GO/PPy and pure PPy. The value represents mean \pm standard deviation $(n=3){ }^{* *} p<0.01$ and ${ }^{*} p<0.05$.

between $10^{\circ}$ and $80^{\circ}$, respectively, which is considered normal hydrophilic with good wettability. Although the water contact angle value of PPy $\left(28.6 \pm 0.8^{\circ}\right)$ was little smaller than that of GO/PPy $\left(34.8 \pm 0.5^{\circ}\right)$, the GO/PPy still presented sufficient hydrophilicity for cell attachment and proliferation [39].

The composition of the one-step electropolymerizationprepared GO/PPy nanocomposite was further analyzed by FTIR. Figure 5 presented the FTIR spectra of GO, pure PPy, and GO/PPy nanocomposite. The GO spectrum revealed the presence of absorption peaks for a few oxygenated functional groups, for example, the stretching vibration peak of the carboxyl group $(\mathrm{C}-\mathrm{OH})$ at $1732 \mathrm{~cm}^{-1}$, the vibration peak of the $-\mathrm{OH}$ group at $3386 \mathrm{~cm}^{-1}$, and the peaks of deformation of $\mathrm{O}-\mathrm{H}$, carbonyl $(\mathrm{C}=\mathrm{O})$, and epoxide $(\mathrm{C}-\mathrm{O}-\mathrm{C})$ at 1400 , 1224 , and $1057 \mathrm{~cm}^{-1}$, respectively. The peak at $1600 \mathrm{~cm}^{-1}$ was related to the characteristics of the residual $\mathrm{sp}^{2}$ from graphene [40]. Compared with GO, several new peaks appeared on the spectrum of GO/PPy nanocomposite because of the presence of PPy. The peaks at 1548, 1448, and $1034 \mathrm{~cm}^{-1}$ were the absorption peaks of the C-C, C-N, and C-H stretching vibration on PPy rings [41]. In addition, the peak of the $\mathrm{C}$ $\mathrm{OH}$ group in the GO/PPy nanocomposite shifted downwards to $1700 \mathrm{~cm}^{-1}$. This shift could be due to the $\pi-\pi$ stacking and hydrogen bonding between the GO nanosheet and the aromatic rings on $\mathrm{Py}$. This result also suggested that the carboxyl groups on GO are the effective doping functional groups in the polymerization of Py [42]. Therefore, FTIR results demonstrated the successful GO doping in PPy film to form the GO/PPy nanocomposite film.

\subsection{Electrochemical Characterizations of GO/PPy Nanocom-} posite. Figure 6(a) showed the Bode plots of EIS results of the bare ITO electrode and ITO electrodes coated with PPy and GO/PPy. Both the modified ITO electrodes showed much smaller impedance than the bare ITO electrode over the frequency range of $1-10^{4} \mathrm{~Hz}$, mainly owing to the effect of PPy [43] and its combination of GO. The lower interfacial impedance of the GO/PPy improved the sensitivity 


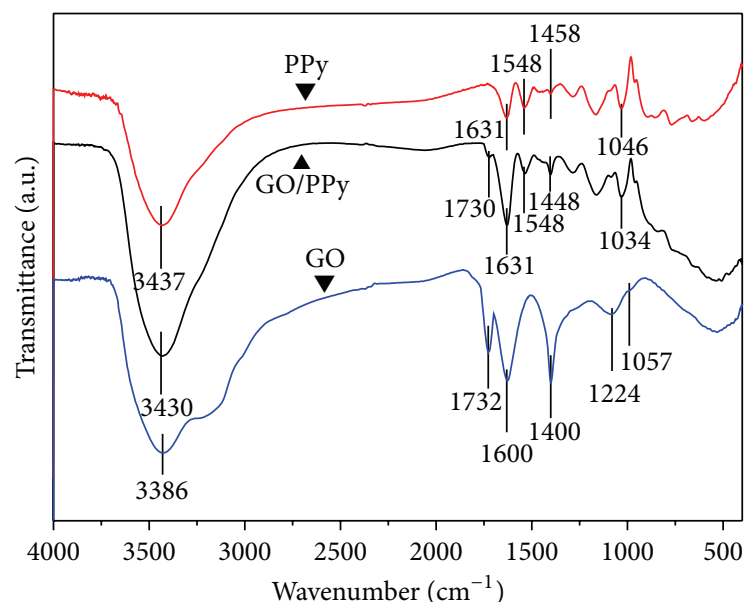

Figure 5: FTIR spectra of GO sheets, pure PPy, and GO/PPy nanocomposite.

of measurements and allowed more reliable measurements at the lower frequencies of the spectrum [35]. Figure 6(b) showed the typical CVs of the bare ITO electrode and ITO electrode modified with GO/PPy and PPy in $0.01 \mathrm{M}$ PBS solution. Compared to the bare ITO electrode, remarkable high capacity was obtained for PPy coated ITO electrode. More importantly, the electrochemical stability was investigated to compare the performances of the GO/PPy and the PPy film. After performing ten CV cycles, the capability of the PPy decreases more than that of GO/PPy. It was found that the GO/PPy retained $95 \%$ of the initial capacitance, which was much higher than that obtained for PPy (74\%). The improved stability obtained for the GO/PPy might be ascribed to the synergistic effect between GO and PPy for the better mechanical strength and ion doping/dedoping mechanism. Based on the discussion mentioned above, it was expected that these novel GO/PPy nanocomposites would be very promising for constructing electrochemical biosensor with improved performance.

\subsection{A549 Cell Culture on the GO/PPy Nanocomposite Film.} The interaction between GO/PPy nanocomposite film and cells was characterized by cell adhesion, spreading, and proliferation. Figure 7 presented the phase contrast image of cells seeded for $2 \mathrm{~h}$ and the spreading laser microscope images of cells seeded for $12 \mathrm{~h}$ on GO/PPy film and PPy film. The cell adhesion images (Figures 7(a) and 7(b)) demonstrated that the A549 cells seeded on GO/PPy film and PPy film exhibited pseudopodia and adhesion, suggesting that the electropolymerized PPy film can support the adhesion of A549 cells. PPy film was able to adsorb proteins in solution, thereby promoting cell adhesion [44]. Figures 7(a) and 7(b) also demonstrated that the spreading proportion of A549 cells was higher on GO/PPy film than on PPy film, which might be due to the difference in the physiochemical properties between the two surfaces, such as surface roughness and hydrophilicity. To further demonstrate the effect of GO/PPy and PPy films on the spreading of A549 cells, the cells seeded on GO/PPy and PPy for $12 \mathrm{~h}$ were observed by laser microscope, as shown in Figures 7(c) and 7(d). The quantity and spreading morphology of A549 cells were better on GO/PPy film than on PPy film. The above results indicated that the GO/PPy film prepared by the onestep electropolymerization can support the adhesion and spreading of A549 cells, providing an excellent biocompatible interface for the cell proliferation.

The relative proliferation activities of A549 cells seeded on polystyrene, GO/PPy, PPy, and bare ITO for $24 \mathrm{~h}$ and $48 \mathrm{~h}$ were analyzed by WST- 8 colorimetric analysis, and the result was presented in Figure 7(e). The relative proliferation activity of A549 cells was significantly higher on GO/PPy film than on polystyrene, PPy, and bare ITO, indicating that GO/PPy exhibited excellent cellular biocompatibility for the proliferation of A549 cells. Additionally, the proliferation rate of A549 cells was the lowest on PPy film, which might be due to the leakage of $\mathrm{Cl}^{-}$ions, which were doped in PPy film during the culture process [44].

3.4. Measurement of the Faradaic Impedance for A549 Cells. Theoretically, the electron transfer resistance of the redox probe on the electrode surface is related to the surface properties of electrodes. When cells adhered to and proliferated on the electrode surface, they inhibited the pathways of the redox probe to reach the electrode surface, resulting in the increase in electron transfer resistance. In addition, the increase in the amplitude of the electron transfer resistance was related to activity and quantity of the cells $[12,45,46]$. Therefore, the detection of cells on the electrode surface could be achieved by measuring the electron transfer impedance for the redox probe. Figure 8(a) presented the Nyquist curves for the bare ITO electrode and GO/PPy-ITO electrode seeded with A549 cells for different times. It demonstrates that the modification of electrodes with GO/PPy nanocomposite film decreased the electron transfer resistance on the electrode surface. At the same time, with the prolonged incubation time of A549 cells, the diameter of the semicircle in the high-frequency region increased, suggesting an increase in electron transfer resistance. The result indicated that A549 cells can proliferate well on the surface of GO/PPy nanocomposite film and that cell proliferation can be detected through the measurement of electron transfer resistance. The relationship between the A549 cell incubation time and the electron transfer resistance $R_{\text {et }}$ of the redox probe was presented in Figure 8(b).

In addition, the proliferation of A549 cells on the surface of GO/PPy nanocomposite film was verified by WST- 8 colorimetric analysis. WST- 8 can be reduced to highly water soluble yellow formazan by dehydrogenase in mitochondria, and the quantity of the resultant formazan is positively correlated with the quantity of live cells. Therefore, the absorbance of formazan can indirectly reflect the quantity of live cells. Correlation analysis was performed between the measured absorbance of WST- 8 and electron transfer resistance $R_{\mathrm{et}}$. The result revealed a correlation coefficient $R=0.986, p<$ 0.01 , indicating an excellent correlation, as presented in Figure 8 (c). Moreover, three parallel experiments revealed that the average precision (RSD $=3.8 \%$ ) of the EIS measurements was better than that of WST-8 measurements (RSD $=7.4 \%)$. 


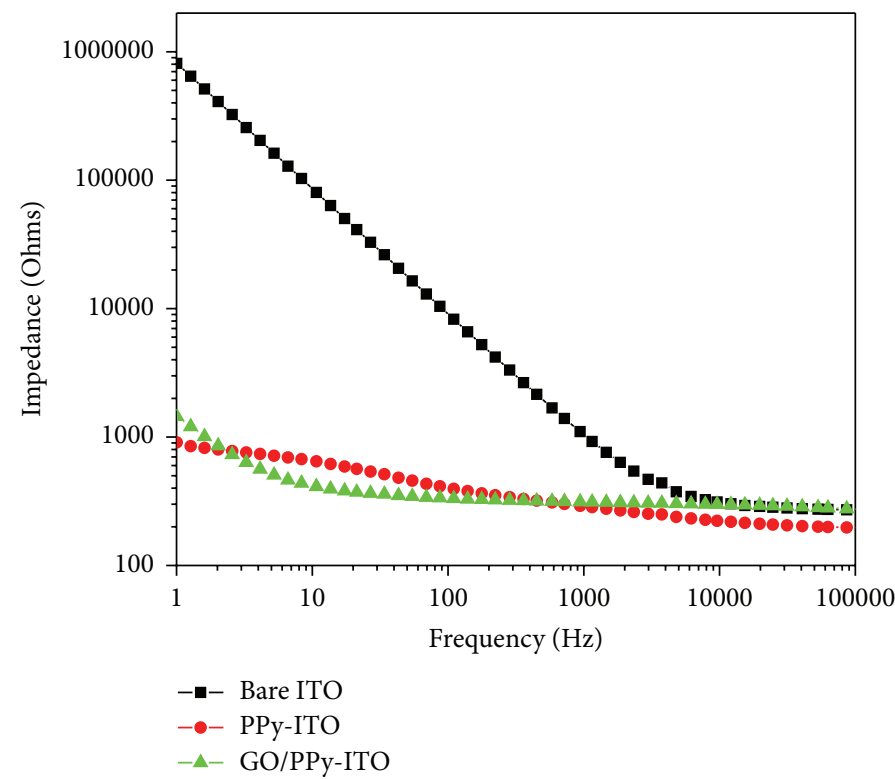

(a)

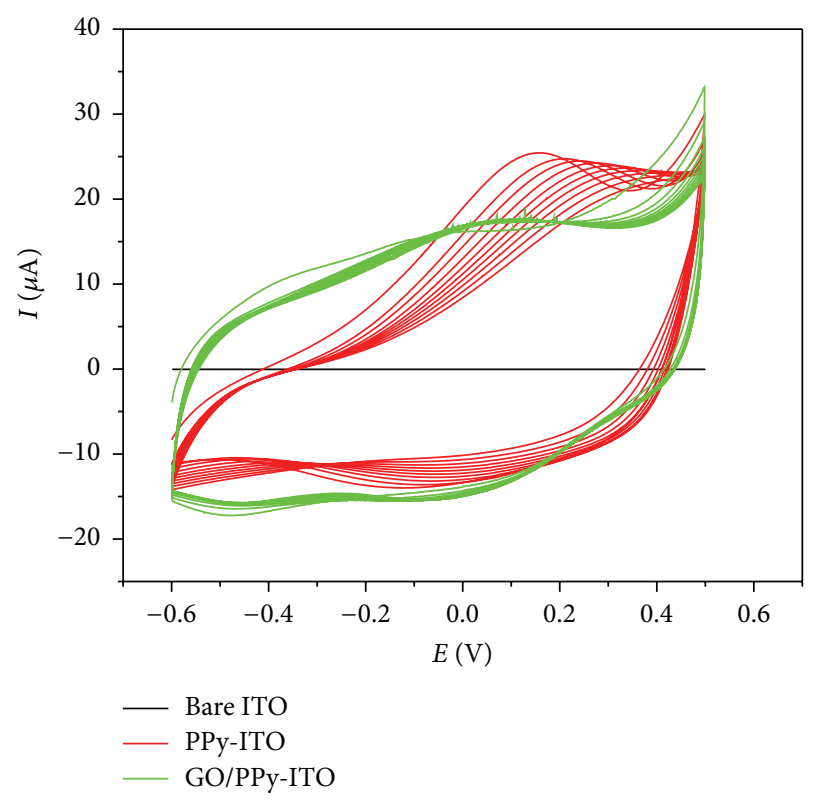

(b)

FIGURE 6: Electrochemical properties of GO/PPy modified ITO electrode. (a) Bode plots of EIS over a frequency range of 1-10 5 Hz in $0.01 \mathrm{M}$ PBS. (b) CV curves of bare ITO electrode and ITO electrodes modified with GO/PPy and PPy, respectively, in $0.01 \mathrm{M}$ PBS at a scan rate of $50 \mathrm{mVs}^{-1}$.

Furthermore, we compared the performances of the different electrode for faradaic EIS detection of A549 cells growth. In order to eliminate the electrode-to-electrode variation, the normalized resistance, $\Delta R_{\mathrm{et}}$, was used for accurate detection: $\Delta R_{\mathrm{et}}=\left(R_{\mathrm{et} 2}-R_{\mathrm{et} 1}\right) / R_{\mathrm{et} 1}$, where $R_{\mathrm{et} 1}$ and $R_{\mathrm{et} 2}$ were the resistance value before and after incubating cells, respectively. Figure $8(\mathrm{~d})$ showed the relationship curves between $\Delta R_{\text {et }}$ and incubation time for different electrodes. It clearly showed that GO/PPy modified ITO electrode revealed the most sensitive performance compared to the bare ITO electrode and PPy modified ITO electrode, further highlighting the advantages of the GO/PPy nanocomposite film as a nanointerface for faradaic cell impedance measurement.

3.5. Measurement of Nonfaradaic Impedance for A549 Cells. The measurement of nonfaradaic impedance for A549 cells was performed in $0.01 \mathrm{M}$ PBS electrolytic solution in the absence of any redox probes. Theoretically, as frequencydependent electronic components, when cells adhere to and proliferate on the surface of microelectrodes, they can cause a change in the impedance characteristics of the electrode system. As a result, the analysis of the impedance spectrum can aid in the analysis of cell adhesion and proliferation on microelectrodes [18, 19, 29, 47]. Figures 9(a) and 9(b) presented the frequency-impedance spectra and the frequencyphase angle spectra for the bare ITO microelectrode and the GO/PPy-ITO microelectrode incubated with A549 cells for different times. They demonstrated that the electropolymerization of GO/PPy nanocomposite film markedly decreased the impedance and phase angle in the low-frequency region
$(1 \sim 1 \mathrm{kHz})$ for the ITO microelectrode, shifted the electrode towards the resistance characteristic, and improved the response characteristics of electrodes in the low-frequency region [35]. The adhesion and proliferation of A549 cells on the surface of the GO/PPy-ITO microelectrode caused the increase in the impedance amplitude for the electrode system over the entire measurement frequency region, as shown in Figure 9(a). This increase was due to the poor conductance of the cells. Furthermore, the cell proliferation produced a new time constant on the frequency-phase angle spectrum in the $30 \sim 40 \mathrm{kHz}$ region, as shown in Figure 9(b). This time constant was speculated to be related to the charging effect of the plasma membrane capacitance [18].

The proliferation of A549 cells on electrodes can be analyzed using the equivalent circuit model. According to the change in the impedance characteristics before and after cell seeding, cells can be considered equivalent to a series of an RC parallel circuit and an R component [35]. Therefore, the equivalent circuit model after seeding with cells consisted of the series of the equivalent circuit of the GO/PPy-ITO microelectrode and the equivalent circuit of cells, as shown in Figure 9(c). Among those, $R_{s}$ explained the gap impedance of the cell-electrode, $R_{\text {cell }}$ explained the gap impedance of the cell-cell, and $C_{\text {cell }}$ explained the capacitance effect of the plasma membrane. The nonlinear least squares method was used to fit the electrochemical impedance data to provide the fitting values of each component for the equivalent circuit of cells at different times, as shown in Figure $9(\mathrm{~d})$. The results demonstrated that, with the adhesion and proliferation of A549 cells, $C_{\text {cell }}$ rapidly increased at $0 \mathrm{~h} \sim$ $24 \mathrm{~h}$ and reached $6.02 \mathrm{nF}$ approximately after the formation 


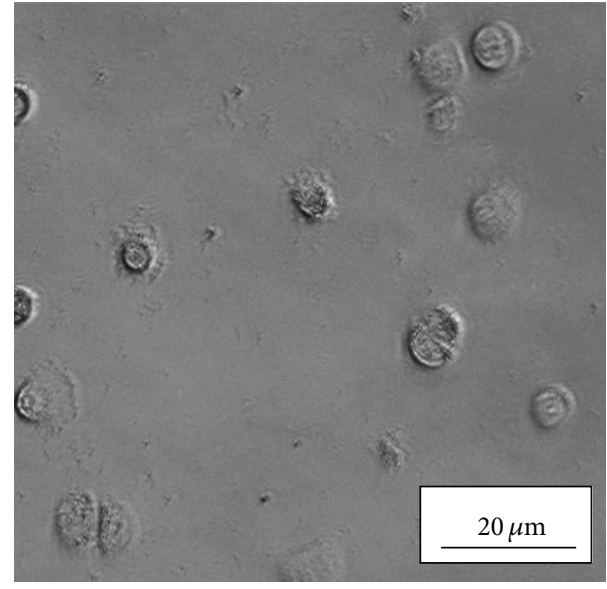

(a)

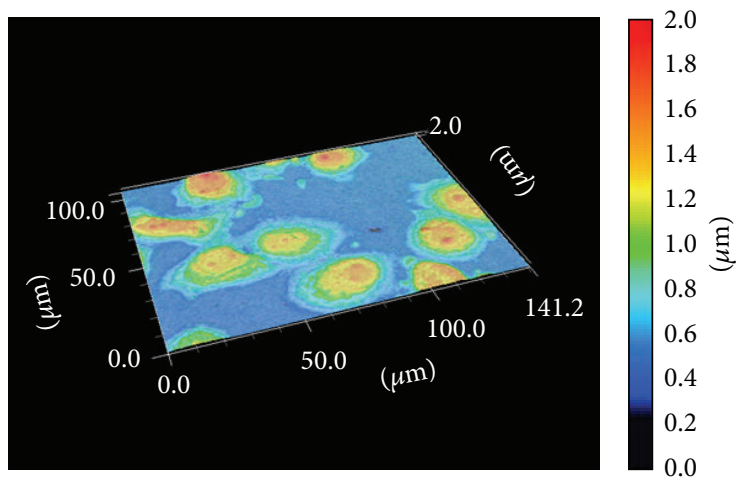

(c)

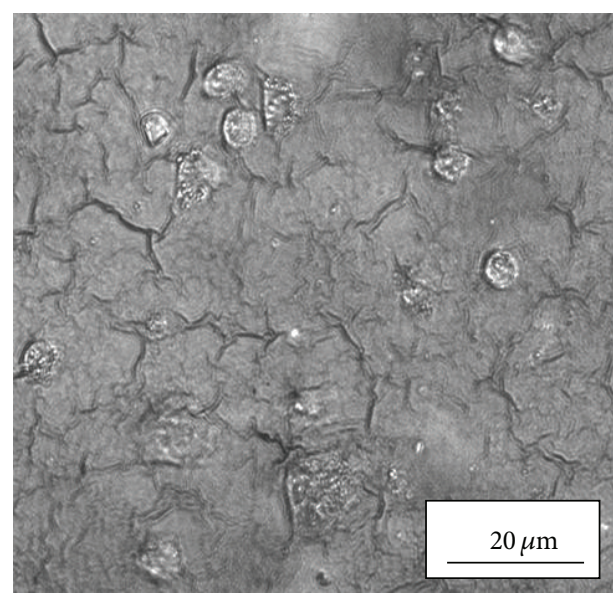

(b)

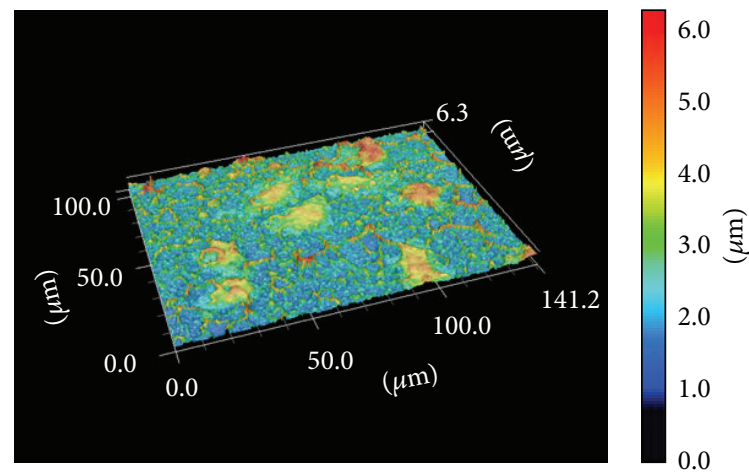

(d)

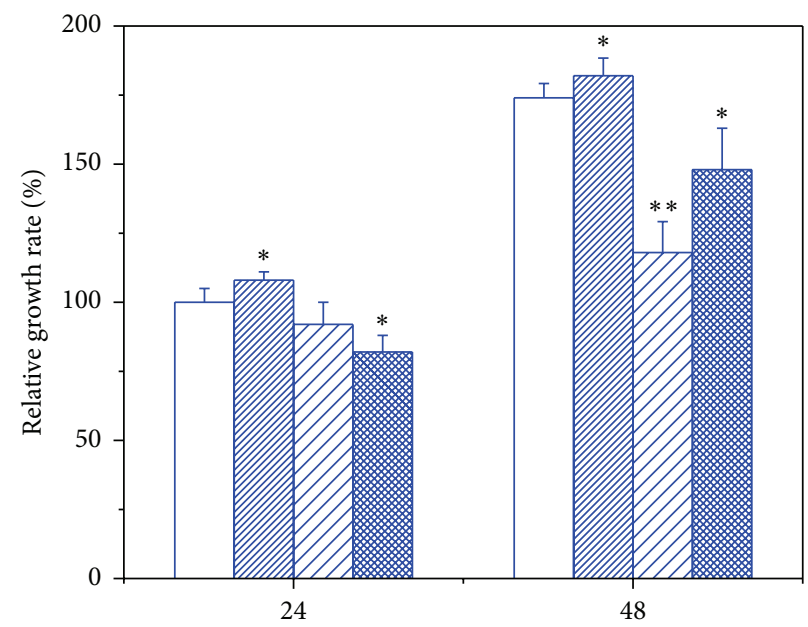

(h)

Polystyrene

DII PPy

GO/PPy

(e)

FIGURE 7: Biocompatibility characterization. Phase contract microscopy images of A549 cells attached to (a) GO/PPy film and (b) PPy film for $2 \mathrm{~h}$ after the inoculation of cells. 3D laser microscope images of A549 cells spread on (c) GO/PPy film and (d) PPy film for $12 \mathrm{~h}$ after seeding. (e) Relative cell growth rate of A549 cells cultured on polystyrene, GO/PPy, PPy, and bare ITO as tested by the WST-8 assay. The absorbance of the WST- 8 solution by polystyrene for $24 \mathrm{~h}$ after cell seeding was used as a control. The value represents mean \pm standard deviation $(n=3)$. ${ }^{* *} p<0.01$ and ${ }^{*} p<0.05$, versus polystyrene. 


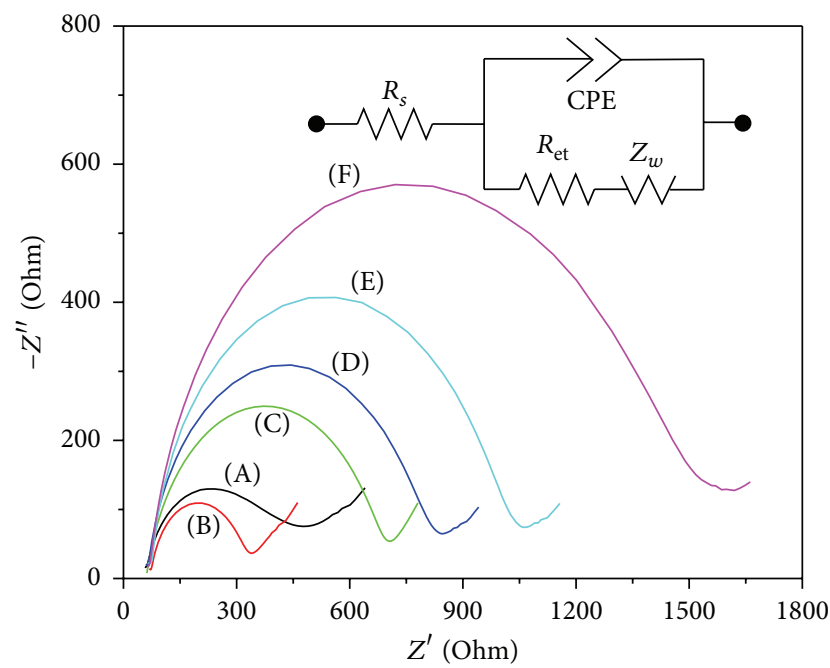

(a)

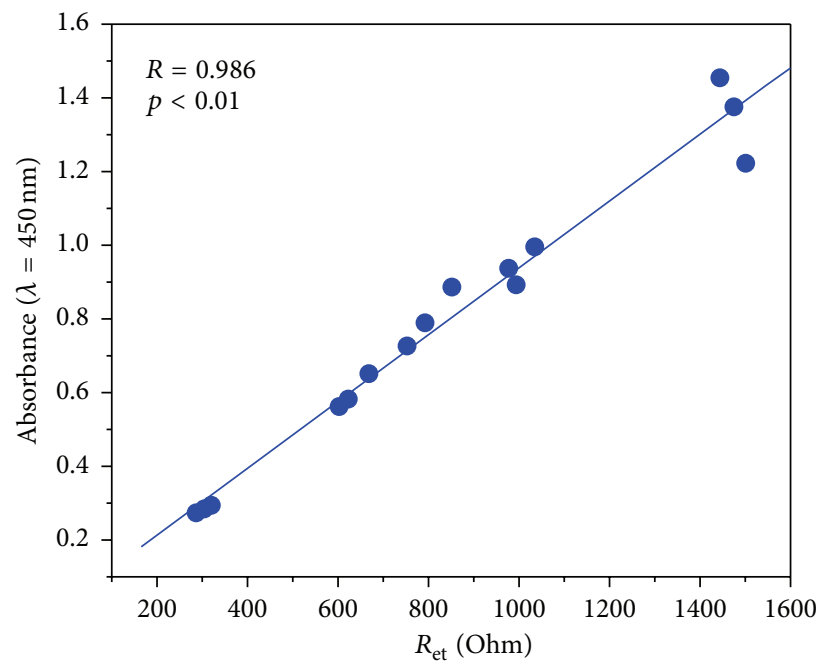

(c)

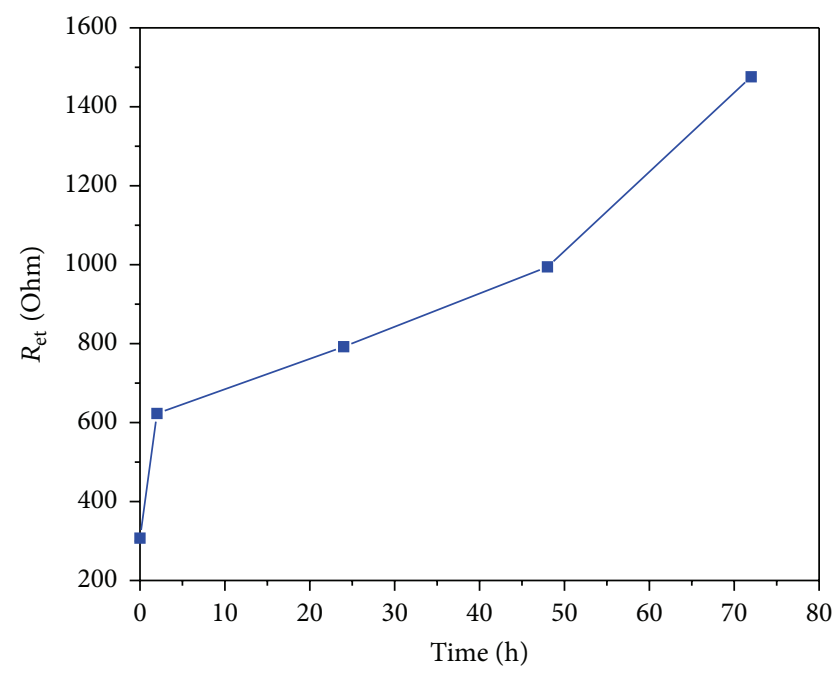

(b)

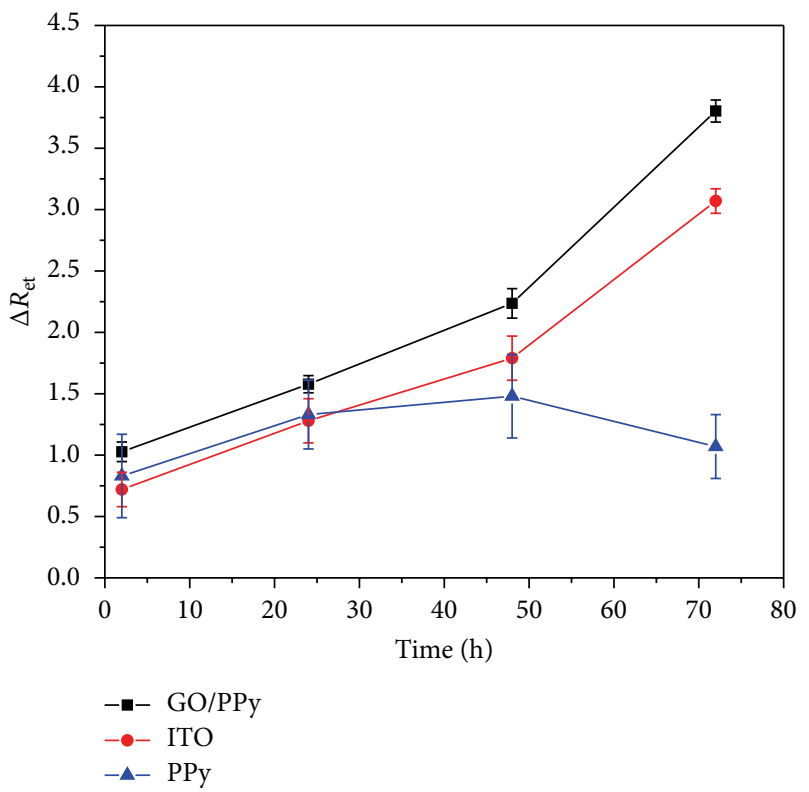

(d)

FIGURE 8: Cell adhesion and proliferation behaviors on GO/PPy-ITO electrode measured by Faraday electrochemical impedance spectroscopy. (a) Faraday electrochemical impedance spectra recorded on bare ITO (A) and GO/PPy nanocomposite film-modified ITO electrode (B) and after A549 cell incubation on a GO/PPy nanocomposite film-modified ITO electrode for $2 \mathrm{~h}$ (C), $24 \mathrm{~h}$ (D), $48 \mathrm{~h}$ (E), and $72 \mathrm{~h}$ (F). (b) Relationship curve between electron transfer resistance $R_{\mathrm{et}}$ and the A549 incubation time. (c) Correlation analysis between the absorbance measured by WST- 8 and electron transfer resistance $R_{\mathrm{et}}$. (d) Relationship curves between the normalized electron transfer resistance $\Delta R_{\mathrm{et}}$ and incubation time for different electrodes.

of the cell monolayer $(48 \sim 72 \mathrm{~h})$. The change in $C_{\text {cell }}$ was related to the decrease in cell thickness, the increase in the spreading area, and the quantity and opening of cellular ion channels in the proliferation process $[19,31] . R_{\text {cell }}$ continuously increased during cell proliferation and reached a maximum at $72 \mathrm{~h}$ (approximately $1873 \Omega$ ). The continuous increase in $R_{\text {cell }}$ indicated that the gap between the cells decreased and that the degree of cell fusion increased [48]. In addition, $R_{s}$ reached a maximum (approximately $183 \Omega$ ) at $48 \mathrm{~h}$ after seeding and decreased to $164 \Omega$ at approximately
$72 \mathrm{~h}$. The change in $R_{s}$ indicated that, at $48 \mathrm{~h}$, the gap between cells and the GO/PPy-ITO electrode was minimal and that the cell adhesion strength was the greatest. Further cell proliferation resulted in an increase in the gaps between cells and the GO/PPy-ITO electrode and the exfoliation of cells [48]. Therefore, the GO/PPy nanocomposite film can also be used as a biological cell-electrochemical detection interface for nonfaradaic impedance measurement to reveal biological information concerning the A549 cell adhesion and proliferation processes. 


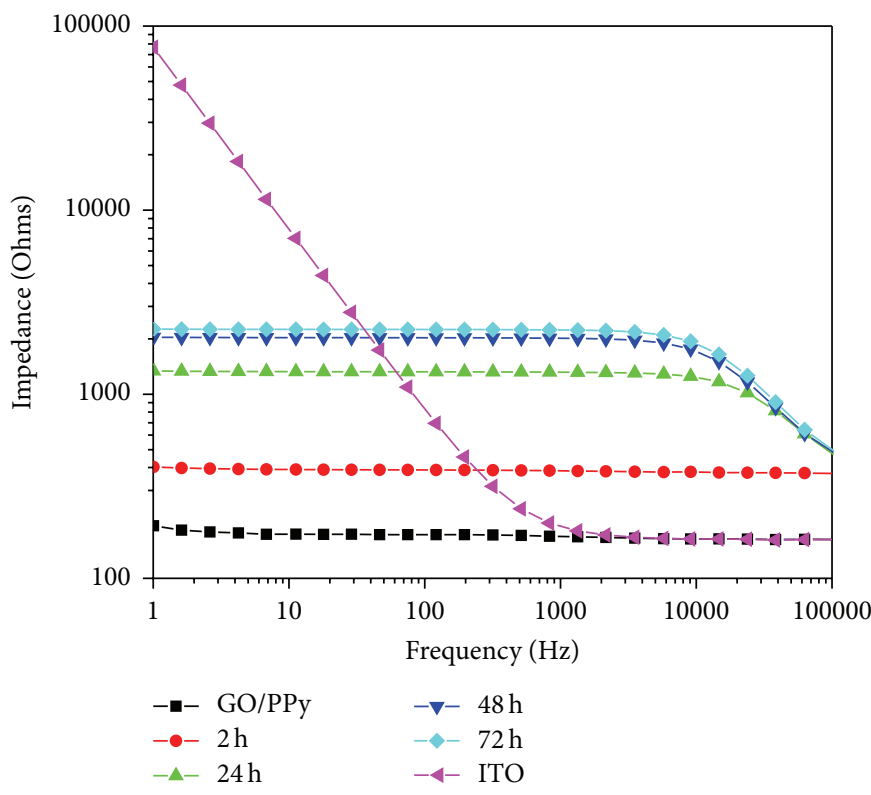

(a)

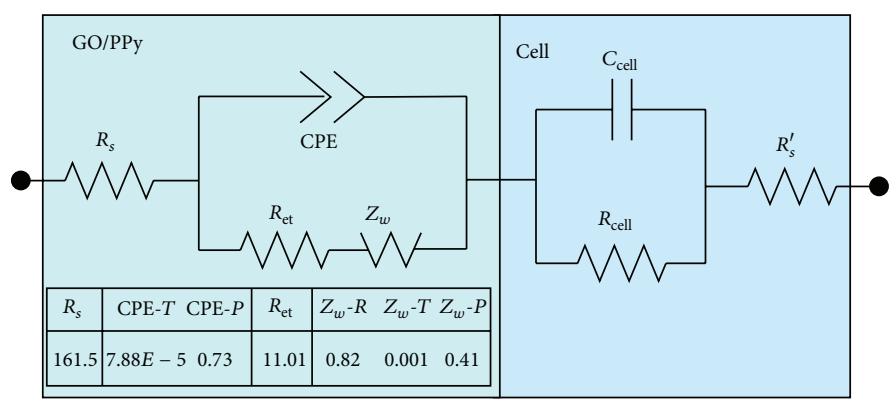

(c)

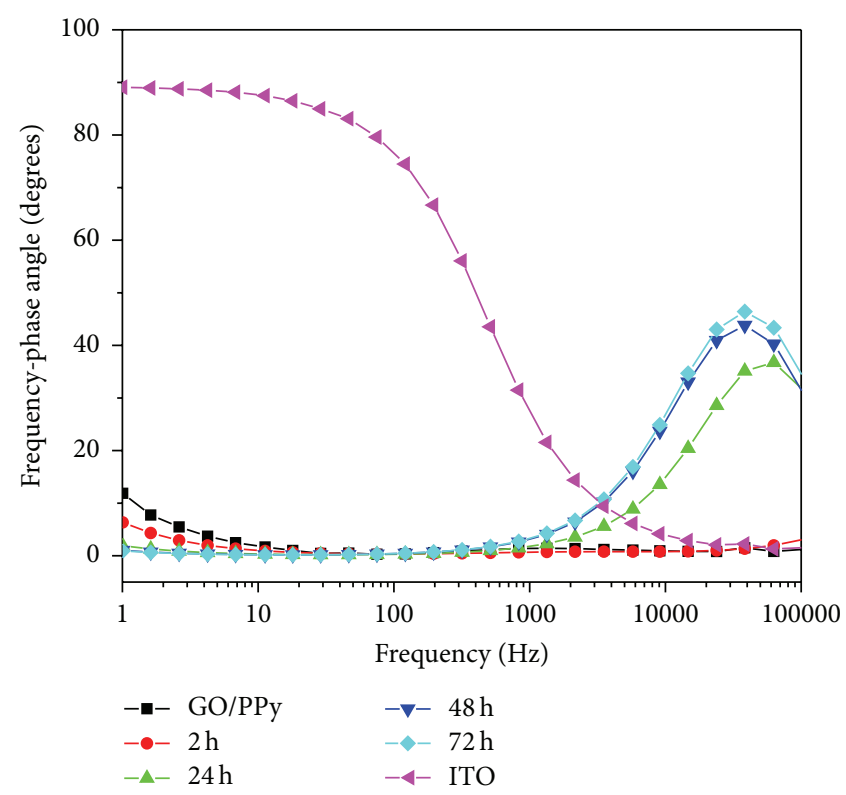

(b)
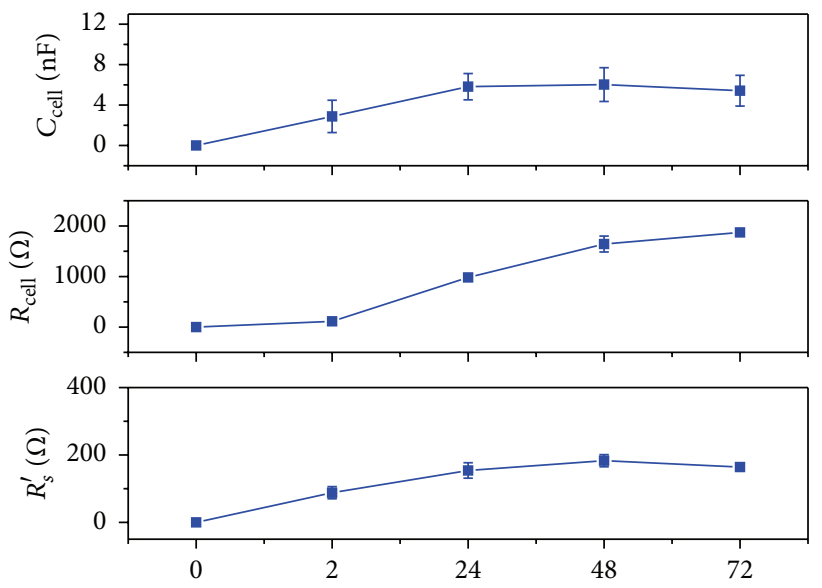

(h)

(d)

FIGURE 9: Cell adhesion and proliferation behaviors on GO/PPy-ITO microelectrodes measured by non-Faraday electrochemical impedance spectroscopy. (a) Typical Bode plot of electrochemical impedance spectra of bare ITO and GO/PPy-ITO microelectrodes recorded at $0 \mathrm{~h}, 2 \mathrm{~h}$, $24 \mathrm{~h}, 48 \mathrm{~h}$, and $72 \mathrm{~h}$ after inoculation of A549 cells. (b) Typical phase plot of electrochemical impedance spectra of bare ITO and GO/PPyITO microelectrodes recorded at $0 \mathrm{~h}, 2 \mathrm{~h}, 24 \mathrm{~h}, 48 \mathrm{~h}$, and $72 \mathrm{~h}$ after inoculation of A549 cells. (c) Equivalent circuit model of the GO/PPy-ITO microelectrode (left) and equivalent circuit model of the cells (right) in series. (d) Curve fit results for the equivalent circuit model of A549 cells after inoculation on GO/PPy-ITO microelectrodes at different times.

\section{Conclusions}

GO/PPy nanocomposite film was synthesized in situ on the surface of ITO electrodes using a one-step electropolymerization technique and was proved to be used as a nanointerface for electrochemical impedance detection of A549 cell adhesion and proliferation. The obtained GO/PPy films exhibited robust interface characterizations and good electrochemical properties. Cell culture and electrochemical impedance measurement experiments demonstrated that
GO/PPy nanocomposite film not only supported A549 cell adhesion and proliferation but also provided a new nanointerface for the measurement of cell adhesion and proliferation by electrochemical impedance spectroscopy. More importantly, the detection of cell adhesion and proliferation on GO/PPy nanocomposite film was achieved by both faradaic impedance and nonfaradaic impedance techniques. Therefore, the cell behaviors could be analyzed from two levels, thus yielding more cell behavior information. Thus, the one-step electropolymerized GO/PPy nanocomposite can be 
used as a robust nanointerface between biological cells and electrochemical impedance system for the fabrication of cellbased impedance biosensors.

\section{Competing Interests}

The authors declare that there are no competing interests regarding the publication of this paper.

\section{Acknowledgments}

This study is supported financially by the Natural Science Foundation Project of CQ (cstc2012jjA10046), Innovation Ability Construction Platform Project of Yongchuan District (ycstc2014bf5001), and Key Research Project of Yongchuan Hospital, Chongqing Medical University (YJZD201302).

\section{References}

[1] H. N. Lim, N. M. Huang, S. S. Lim, I. Harrison, and C. H. Chia, "Fabrication and characterization of graphene hydrogel via hydrothermal approach as a scaffold for preliminary study of cell growth," International Journal of Nanomedicine, vol. 6, pp. 1817-1823, 2011.

[2] F. Song, X. Li, Q. Wang, L. Liao, and C. Zhang, "Nanocomposite hydrogels and their applications in drug delivery and tissue engineering," Journal of Biomedical Nanotechnology, vol. 11, no. 1, pp. 40-52, 2015.

[3] Y. S. Gao, J. K. Xu, L. M. Lu et al., "Overoxidized polypyrrole/graphene nanocomposite with good electrochemical performance as novel electrode material for the detection of adenine and guanine," Biosensors and Bioelectronics, vol. 62, pp. 261-267, 2014.

[4] D. R. Dreyer, S. Park, C. W. Bielawski, and R. S. Ruoff, "The chemistry of graphene oxide," Chemical Society Reviews, vol. 39, no. 1, pp. 228-240, 2010.

[5] H. H. Zhou, G. Y. Han, Y. M. Xiao, Y. Z. Chang, and H.-J. Zhai, "Facile preparation of polypyrrole/graphene oxide nanocomposites with large areal capacitance using electrochemical codeposition for supercapacitors," Journal of Power Sources, vol. 263, no. 1, pp. 259-267, 2014.

[6] Y. Mao, Y. Chen, S. Li, S. Lin, and Y. Jiang, "A graphene-based biosensing platform based on regulated release of an aptameric DNA biosensor," Sensors, vol. 15, no. 11, pp. 28244-28256, 2015.

[7] H. Chen, J. Zhang, Y. Gao et al., "Sensitive cell apoptosis assay based on caspase-3 activity detection with graphene oxideassisted electrochemical signal amplification," Biosensors and Bioelectronics, vol. 68, pp. 777-782, 2015.

[8] F. Lin, X. Tong, Y. Wang, J. Bao, and Z. M. Wang, "Graphene oxide liquid crystals: synthesis, phase transition, rheological property, and applications in optoelectronics and display," Nanoscale Research Letters, vol. 10, article 435, 2015.

[9] Y. Yang, H. Shi, Y. Wang et al., "Graphene oxide/manganese ferrite nanohybrids for magnetic resonance imaging, photothermal therapy and drug delivery," Journal of Biomaterials Applications, vol. 30, no. 6, pp. 810-822, 2016.

[10] Y. Chang, S.-T. Yang, J.-H. Liu et al., "In vitro toxicity evaluation of graphene oxide on A549 cells," Toxicology Letters, vol. 200, no. 3, pp. 201-210, 2011.

[11] M. Park, H. Choi, Y. Park, W. Lee, J. Lee, and M. Jeon, "Fabrication and characterization of graphene-based electrochemical sensors for glucose measurement," Journal of Nanoscience and Nanotechnology, vol. 15, no. 10, pp. 7891-7894, 2015.

[12] D. Zhang, Y. Zhang, L. Zheng, Y. Zhan, and L. He, "Graphene oxide/poly-l-lysine assembled layer for adhesion and electrochemical impedance detection of leukemia K562 cancer cells," Biosensors and Bioelectronics, vol. 42, no. 1, pp. 112-118, 2013.

[13] C. X. Guo, S. R. Ng, S. Y. Khoo, X. Zheng, P. Chen, and C. M. $\mathrm{Li}$, "RGD-peptide functionalized graphene biomimetic live-cell sensor for real-time detection of nitric oxide molecules," ACS Nano, vol. 6, no. 8, pp. 6944-6951, 2012.

[14] M. A. Booth, S. Harbison, and J. Travas-Sejdic, "Development of an electrochemical polypyrrole-based DNA sensor and subsequent studies on the effects of probe and target length on performance," Biosensors and Bioelectronics, vol. 28, no. 1, pp. 362-367, 2011.

[15] J. G. Ayenimo and S. B. Adeloju, "Inhibitive potentiometric detection of trace metals with ultrathin polypyrrole glucose oxidase biosensor," Talanta, vol. 137, pp. 62-70, 2015.

[16] J.-M. Moon, Y. Hui Kim, and Y. Cho, "A nanowire-based labelfree immunosensor: direct incorporation of a PSA antibody in electropolymerized polypyrrole," Biosensors and Bioelectronics, vol. 57, pp. 157-161, 2014.

[17] A. Fahlgren, C. Bratengeier, A. Gelmi et al., "Biocompatibility of polypyrrole with human primary osteoblasts and the effect of dopants," PLoS ONE, vol. 10, no. 7, article e0134023, 2015.

[18] D. D. Ateh, A. Waterworth, D. Walker, B. H. Brown, H. Navsaria, and P. Vadgama, "Impedimetric sensing of cells on polypyrrolebased conducting polymers," Journal of Biomedical Materials Research. Part A, vol. 83, no. 2, pp. 391-400, 2007.

[19] Y. Li, G. L. Yuan, C. Y. Xia, and C. Yu, "Construction of a cell impedance biosensor based on polypyrrole-indium tin oxide micro-electrode for detecting cell biology behavior," Chinese Journal of Analytical Chemistry, vol. 43, no. 12, pp. 1844-1850, 2015.

[20] W. Chen, Z. Lu, and C. M. Li, "Sensitive human interleukin 5 impedimetric sensor based on polypyrrole-pyrrolepropylic acid-gold nanocomposite," Analytical Chemistry, vol. 80, no. 22, pp. 8485-8492, 2008.

[21] S.-H. Roh, "Electricity generation from microbial fuel cell with polypyrrole-coated carbon nanofiber composite," Journal of Nanoscience and Nanotechnology, vol. 15, no. 2, pp. 1700-1703, 2015.

[22] S. Li, K. Shu, C. Zhao et al., "One-step synthesis of graphene/ polypyrrole nanofiber composites as cathode material for a biocompatible zinc/polymer battery," ACS Applied Materials and Interfaces, vol. 6, no. 19, pp. 16679-16686, 2014.

[23] P. A. Mini, A. Balakrishnan, S. V. Nair, and K. R. V. Subramanian, "Highly super capacitive electrodes made of graphene/ poly(pyrrole)," Chemical Communications, vol. 47, no. 20, pp. 5753-5755, 2011.

[24] S. Biswas and L. T. Drzal, "Multilayered nanoarchitecture of graphene nanosheets and polypyrrole nanowires for high performance supercapacitor electrodes," Chemistry of Materials, vol. 22, no. 20, pp. 5667-5671, 2010.

[25] C. Zhu, J. Zhai, D. Wen, and S. Dong, "Graphene oxide/ polypyrrole nanocomposites: one-step electrochemical doping, coating and synergistic effect for energy storage," Journal of Materials Chemistry, vol. 22, no. 13, pp. 6300-6306, 2012.

[26] Z. Lv, Y. Chen, H. Wei et al., "One-step electrosynthesis of polypyrrole/graphene oxide composites for microbial fuel cell application," Electrochimica Acta, vol. 111, pp. 366-373, 2013. 
[27] M. Deng, X. Yang, M. Silke et al., "Electrochemical deposition of polypyrrole/graphene oxide composite on microelectrodes towards tuning the electrochemical properties of neural probes," Sensors and Actuators, B: Chemical, vol. 158, no. 1, pp. 176-184, 2011.

[28] Y. Hu, P. Zuo, and B.-C. Ye, "Label-free electrochemical impedance spectroscopy biosensor for direct detection of cancer cells based on the interaction between carbohydrate and lectin," Biosensors and Bioelectronics, vol. 43, no. 1, pp. 79-83, 2013.

[29] I. Giaever and C. R. Keese, "Micromotion of mammalian cells measured electrically," Proceedings of the National Academy of Sciences of the United States of America, vol. 88, no. 17, pp. 78967900, 1991.

[30] D. Schneider, M. Tarantola, and A. Janshoff, "Dynamics of TGF$\beta$ induced epithelial-to-mesenchymal transition monitored by Electric Cell-Substrate Impedance Sensing," Biochimica et Biophysica Acta - Molecular Cell Research, vol. 1813, no. 12, pp. 2099-2107, 2011.

[31] J. Hong, K. Kandasamy, M. Marimuthu, C. S. Choi, and S. Kim, "Electrical cell-substrate impedance sensing as a non-invasive tool for cancer cell study," Analyst, vol. 136, no. 2, pp. 237-245, 2011.

[32] X. Sun, J. Ji, D. Jiang et al., "Development of a novel electrochemical sensor using pheochromocytoma cells and its assessment of acrylamide cytotoxicity," Biosensors and Bioelectronics, vol. 44, no. 1, pp. 122-126, 2013.

[33] C. K. Choi, A. E. English, S.-I. Jun, K. D. Kihm, and P. D. Rack, "An endothelial cell compatible biosensor fabricated using optically thin indium tin oxide silicon nitride electrodes," Biosensors and Bioelectronics, vol. 22, no. 11, pp. 2585-2590, 2007.

[34] T. Patois, B. Lakard, S. Monney, X. Roizard, and P. Fievet, "Characterization of the surface properties of polypyrrole films: influence of electrodeposition parameters," Synthetic Metals, vol. 161, no. 21-22, pp. 2498-2505, 2011.

[35] A. S. Karimullah, D. R. S. Cumming, M. Riehle, and N. Gadegaard, "Development of a conducting polymer cell impedance sensor," Sensors and Actuators B: Chemical, vol. 176, pp. 667-674, 2013.

[36] L. L. Zhang, S. Zhao, X. N. Tian, and X. S. Zhao, "Layered graphene oxide nanostructures with sandwiched conducting polymers as supercapacitor electrodes," Langmuir, vol. 26, no. 22, pp. 17624-17628, 2010.

[37] R. Balint, N. J. Cassidy, and S. H. Cartmell, "Conductive polymers: towards a smart biomaterial for tissue engineering," Acta Biomaterialia, vol. 10, no. 6, pp. 2341-2353, 2014.

[38] M. Vandrovcová and L. Bačáková, "Adhesion, growth and differentiation of osteoblasts on surface-modified materials developed for bone implants," Physiological Research, vol. 60, no. 3, pp. 403-417, 2011.

[39] C. Tlili, K. Reybier, A. Géloën et al., "Fibroblast cells: a sensing bioelement for glucose detection by impedance spectroscopy," Analytical Chemistry, vol. 75, no. 14, pp. 3340-3344, 2003.

[40] C. Zhu, S. Guo, P. Wang et al., "One-pot, water-phase approach to high-quality graphene/ $\mathrm{TiO}_{2}$ composite nanosheets," Chemical Communications, vol. 46, no. 38, pp. 7148-7150, 2010.

[41] S. Bose, T. Kuila, M. E. Uddin, N. H. Kim, A. K. T. Lau, and J. H. Lee, "In-situ synthesis and characterization of electrically conductive polypyrrole/graphene nanocomposites," Polymer, vol. 51, no. 25, pp. 5921-5928, 2010.
[42] R. Bissessur, P. K. Y. Liu, and S. F. Scully, "Intercalation of polypyrrole into graphite oxide," Synthetic Metals, vol. 156, no. 16-17, pp. 1023-1027, 2006.

[43] A. Gelmi, M. J. Higgins, and G. G. Wallace, "Physical surface and electromechanical properties of doped polypyrrole biomaterials," Biomaterials, vol. 31, no. 8, pp. 1974-1983, 2010.

[44] A. Gelmi, M. K. Ljunggren, M. Rafat, and E. W. H. Jager, "Influence of conductive polymer doping on the viability of cardiac progenitor cells," Journal of Materials Chemistry B, vol. 2, no. 24, pp. 3860-3867, 2014.

[45] A. Venkatanarayanan, T. E. Keyes, and R. J. Forster, "Label-free impedance detection of cancer cells," Analytical Chemistry, vol. 85, no. 4, pp. 2216-2222, 2013.

[46] L. Ding, C. Hao, X. J. Zhang, and H. X. Ju, "Carbon nanofiber doped polypyrrole nanoscaffold for electrochemical monitoring of cell adhesion and proliferation," Electrochemistry Communications, vol. 11, no. 4, pp. 760-763, 2009.

[47] T. B. Tran, P. D. Nguyen, S. H. Um, S. J. Son, and J. Min, "Realtime monitoring in vitro cellular cytotoxicity of silica nanotubes using electric cell-substrate impedance sensing (ECIS)," Journal of Biomedical Nanotechnology, vol. 9, no. 2, pp. 286-290, 2013.

[48] K. Benson, S. Cramer, and H.-J. Galla, "Impedance-based cell monitoring: barrier properties and beyond," Fluids and Barriers of the CNS, vol. 10, no. 1, article 5, 2013. 

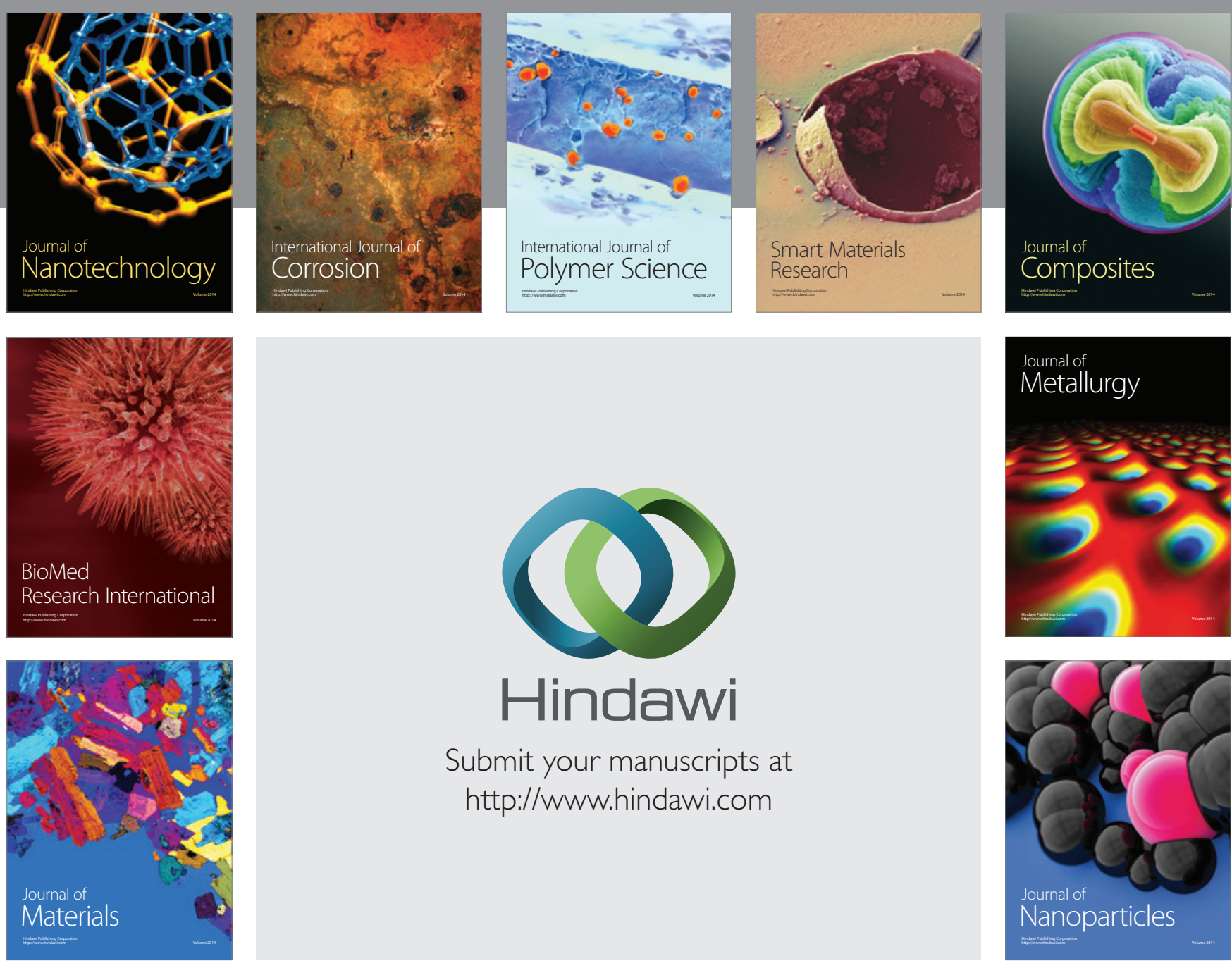

\section{Hindawi}

Submit your manuscripts at

http://www.hindawi.com

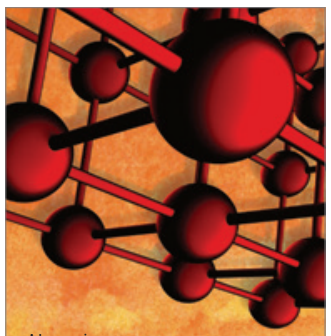

Materials Science and Engineering
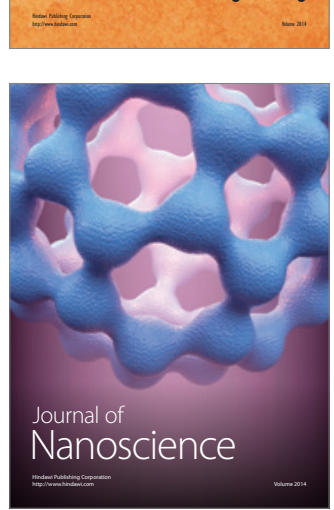
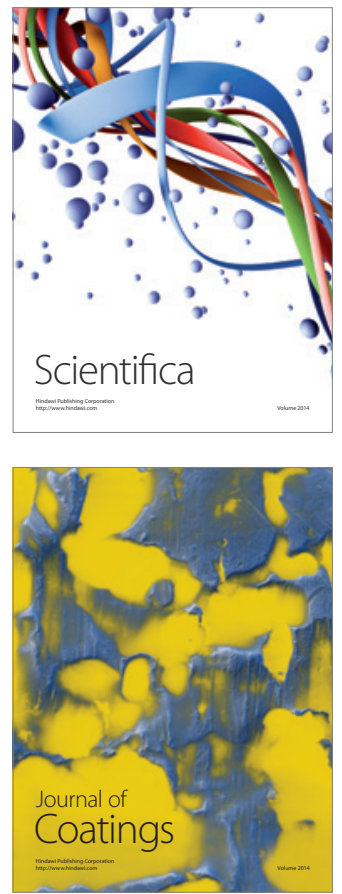
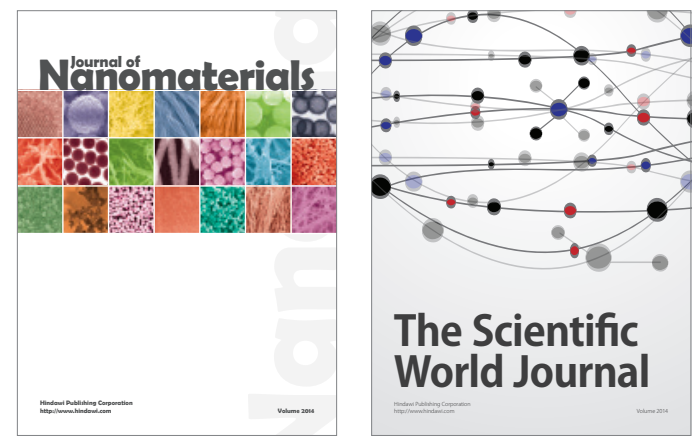

The Scientific World Journal
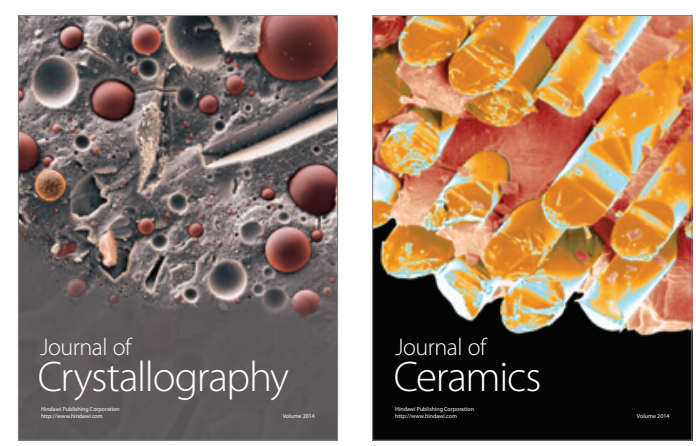
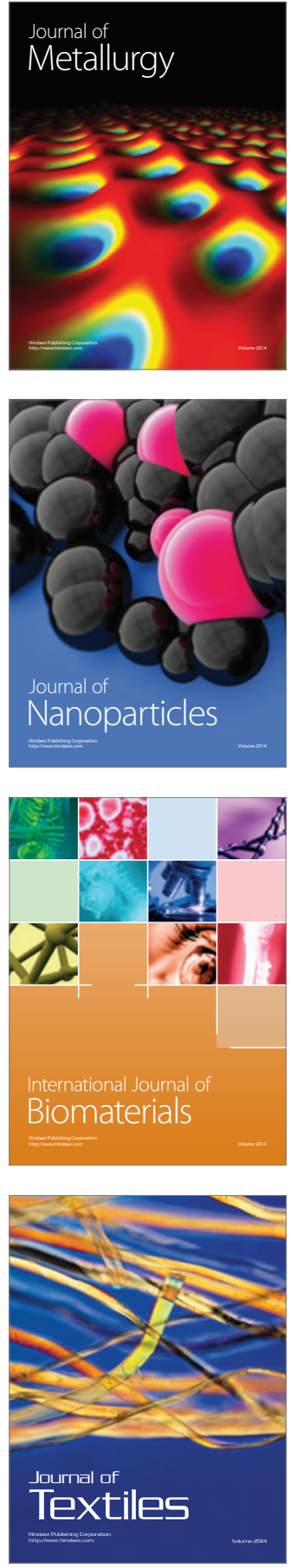